\title{
Intraosseous anesthesia in symptomatic irreversible pulpitis: Impact of bone thickness on perception and duration of pain
}

\author{
Manfred Nilius', Charlotte Mueller', Minou Helene Nilius', Dominik Haim², Henry Leonhardt', Guenter Lauer $^{2}$ \\ ${ }^{1}$ Niliusklinik, Londoner Bogen 6, D-44269 Dortmund, Germany \\ ${ }^{2}$ Technische Universität Dresden, University Hospital "Carl Gustav Carus", Department of Oral and Maxillofacial Surgery, Dresden, Germany
}

\begin{abstract}
Background: Intraosseous anesthesia (IO) allows the anesthetic solution to be injected directly into the cancellous bone. The anesthetic solution immediately reaches the periapical region, and thus the axonal area of the nerve, where it can temporarily disable the sodium pump. The effect is felt almost without any time delay, and only a small amount of anesthetic solution is required.

Methods: This study aims to investigate the efficacy of IO using the Anesto ${ }^{\circledR}$ device after infiltration anesthesia (IA) and/or inferior alveolar nerve block anesthesia (IANB) failed to work in symptomatic irreversible pulpitis (hot tooth). The 33 patients included in the study were treated additionally with $1.7 \mathrm{ml}$ articaine hydrochloride with 1:100,000 epinephrine hydrochloride (Ultracain ${ }^{\circledR}$ D-S, Sanofi-Aventis, Frankfurt, Germany) IO.

Results: The electrical pulp test showed that $95.76 \%$ of the volunteers reacted positively to the combination of IANB or IA with the IO. In women, the additive IO was effective at $97.22 \%$. In men, the IO led to pain elimination in $94.00 \%$ of cases. The duration of the IO was less than a quarter of an hour (13.03 min). The IO worked longer in women than in men (13.61 min vs. $12.33 \mathrm{~min})$. Overall, more than every third tooth that needed trepanation was located in the posterior area of the mandible $(36.4 \%)$. Treatment of hot teeth in this area was associated with an increased pulse rate and increased residual pain. There was a moderate correlation (Spearman-Rho $[\mathrm{IRI}]=0.280$ ) between the Visual Analog Scale (VAS) score and bone density, and a significant correlation (IRI $=0.612$ ) between subjective residual pain and bone width. The IO resulted in a moderate, transient increase in the pulse rate by approximately $20 \mathrm{bpm}$. This is similar to the temporary increase in heart rate after conventional anesthesia techniques in non-preloaded patients and can be considered clinically irrelevant.

Conclusion: IO with the Anesto ${ }^{\circledR}$ device as an extension and deepening of local pain elimination is recommended for the treatment of hot teeth.
\end{abstract}

Keywords: Anesto ${ }^{\circledR}$ device; Hot tooth; Intraosseous Anesthesia; Irreversible Pulpitis; Local Anesthesia.

This is an Open Access article distributed under the terms of the Creative Commons Attribution Non-Commercial License (http://creativecommons.org/licenses/by-nc/4.0/) which permits unrestricted non-commercial use, distribution, and reproduction in any medium, provided the original work is properly cited.

\section{INTRODUCTION}

Intraosseous anesthesia (IO) allows the anesthetic solution to be injected directly into the cancellous bone. The anesthetic solution immediately reaches the periapical region, and thus the axonal area of the nerve, where it can temporarily disable the sodium pump.

The anesthetic effect can be achieved with almost no time lag, and only a small amount of anesthesia is needed. The transcortical injection technique avoids nerve injuries that are commonly related to the use of intraoral nerve

Received: November 10, 2020 • Revised: November 25, 2020 • Accepted: December 3, 2020

Corresponding Author: Manfred Nilius, Niliusklinik Dortmund, Londoner Bogen 6, 44269 Dortmund, Germany

Tel: +492314764 4764 Fax: +492314764 4765 E-mail: manfrednilius@niliusklinik.de

Copyright@ 2020 Journal of Dental Anesthesia and Pain Medicine 
zblocks in cases of symptomatic pulpitis. Accidental vessel injection or lingual nerve injuries can be prevented [1].

\section{Intention}

The aim of this study was to evaluate the efficacy of intraosseous anesthesia (IO) using the Anesto ${ }^{\circledR}$ device supplementary to infiltration anesthesia (IA) and/or inferior alveolar nerve block anesthesia (IANB) in symptomatic irreversible pulpitis (IP).

This leads to following working assumptions:

- IO improves analgesia in teeth with irreversible pulpitis

- There will be a rapid onset and a short effect of duration with IO

- The majority of hot teeth are found in the mandible with a cortical bone thickness of $>3 \mathrm{~mm}$. Bone width and bone density may be relevant for the perception and duration of painlessness with IO.

- The increase in heart rate in assisting / supplementary IO anesthesia is higher / lower than other methods.

\section{METHODS}

\section{Sampling}

This study was authorized by the Committee for Ethics, Dresden University of Technology, Carl Gustav Carus, Case Ref. no: bo-Antrag-v2.3-468989 2020/09. All patients were thoroughly briefed and consent forms were signed before the interventions.

We examined a total of 115 patients with irreversible pulpitis (18-67y; f 48 and $\mathrm{m} \mathrm{67)}$ ). The patients initially received $1.7 \mathrm{ml}$ Ultracain forte (articaine hydrochloride with 1:100,000 epinephrine hydrochloride) IA or IANB. This study included 33 white German dentate patients with IP in teeth located in various areas of the jaw, who received a combined anesthesia, IA or IANB, and an IO with Anesto ${ }^{\circledR}$ device due to pain resistance after IA or IANB. As there were no quantifiable target populations for the sample size $(\mathrm{N}=33)$, non-probabilistic sampling by criterion was used and a technique was assigned randomly. The patients were treated at the Department of Oral and Maxillofacial Surgery of Niliusklinik, Dortmund, Germany, between January 2018 and December 2019. The patients were at least high school graduates, healthy, and had no systemic diseases. All patients provided informed consent before IO. Anesthetic failure was not observed after IO. The following data were collected:

1. Age: 33 patients with an average age of 36.76 years (20 - 62 years)

2. Gender: 18 female (34 mean), 15 male (38 mean)

3. Jaw areas: (see annex)

4. Bone thickness (width of cortical bone in $\mathrm{mm}$ and bone density [Hounsfield, HU] in CBCT)

5. Residual pain perception (visual analog scale, VAS)

6. Anesthesia time, susceptibility to knocking and percussion

7. Increase of the heart rate $0-30$ min after IO with $1.7 \mathrm{ml}$ Ultracain forte $1: 100000$

\section{The Anesto $^{\circledR}$ system}

The participants with persistent pain after IA and IANB received endodontic treatment with additional analgesia via IO using the Anesto ${ }^{\circledR}$ device. This device consists of a drilling system that penetrates the corticalis to inject the anesthetic solution directly into the cancellous bone. A rotating needle on the dental handpiece enters the corticalis minimally at a predetermined speed of approximately $1 \mathrm{~s}$. Then, the anesthetic solution is injected right into the cancellous bone with no pressure. Before penetrating the corticalis, a surface anesthesia is recommended.

The use of a metering lever for submucosal or intraligamentous injections is also possible. The point and direction of perforation depends on the medical procedure.

In the present study, the area of injection was selected in the dentate jaw by the intersection of the buccal or labial horizontal line, with the interdental vertical line. It is located approximately two $\mathrm{mm}$ above the mucogingival junction to the attached gingiva. 


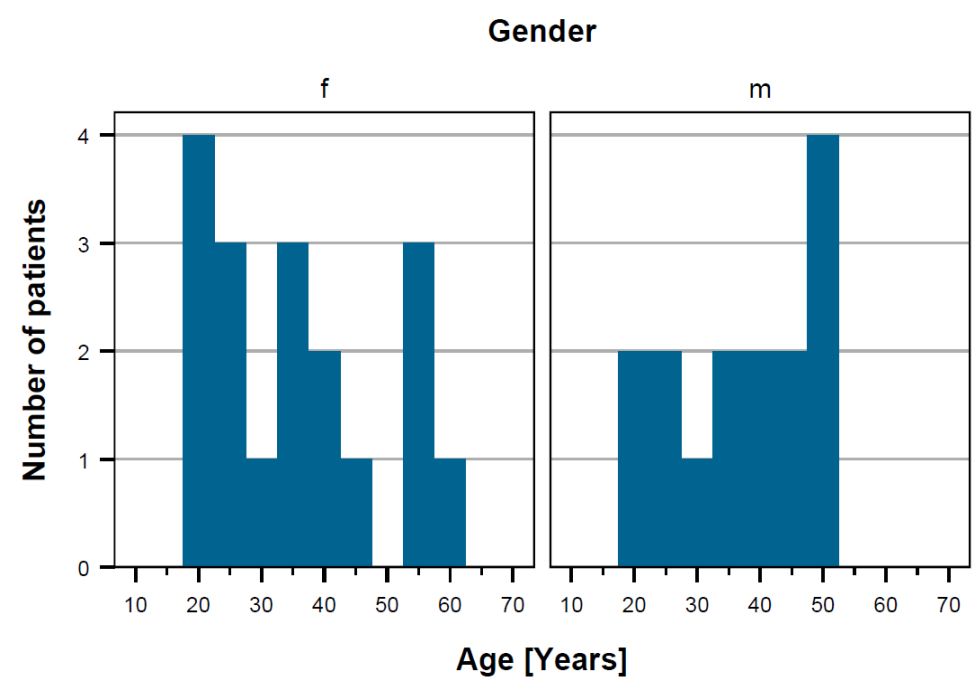

Fig. 1. Distribution of patients according to age and gender

A CBCT-radiography of the dental region was performed after collecting data on anamnesis and clinical examination.

\section{RESULTS}

This study included 33 white German dentate patients with an average age of 36.76 years (20-62 years). Of these, 18 were female and 15 were male. Overall, female patients were slightly younger than the male participants (average 34 vs. 38 years old). The peak age of men and women was 50 years and 20 years, respectively (see Fig. 1). Their residence was geographically located in the western part of Germany. The educational attainment varied from high school to doctorate levels. Their income level was not recorded.

The duration of IO lasted an average of 13.03 min with a standard deviation (STD) of $4.99 \mathrm{~min}$. The minimal time of anesthesia was documented as $5 \mathrm{~min}$ and the longest was $20 \mathrm{~min}$, with the average calculated as $15.00 \mathrm{~min}$. Of all the participants, $95.76 \%$ responded positively to the IO.

Women and men reacted differently to the IO. In females, IO had a positive analgesic effect (97.22\%), while fewer males reacted positively $(94.00 \%)$. Further-

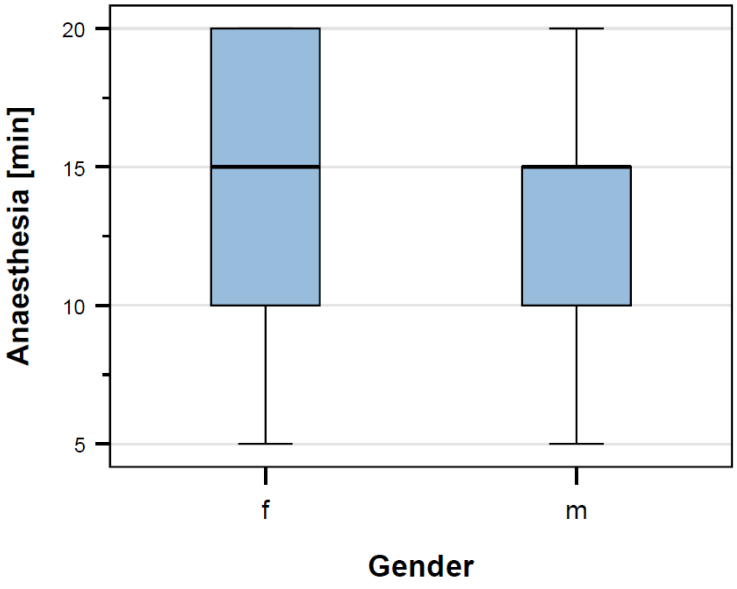

Fig. 2. Anesthetic duration of 10 (min) corresponding to gender

more, the IO lasted longer in female than in male patients (13.61 min vs. $12.33 \mathrm{~min}$ ) (see Fig. 2).

In the lower molar regions, there were eight teeth with pulpitis problems in the female group (44.4\%) and four in the male group (26.7\%). Thus, three of four teeth that needed endodontic treatment were located in the posterior mandible region $(36.4 \%)$.

Optimal efficacy of IO was achieved at the upper cuspid (upper canine $=\mathrm{UC}$ ) regions $(100 \%)$. The slightest impact was found in the upper premolar regions (UP) at $92 \%$. The anesthesia lasted the longest (with an average of $18.75 \mathrm{~min}$ ) in the female's lower molar regions.

The residual pain level was assessed individually by 


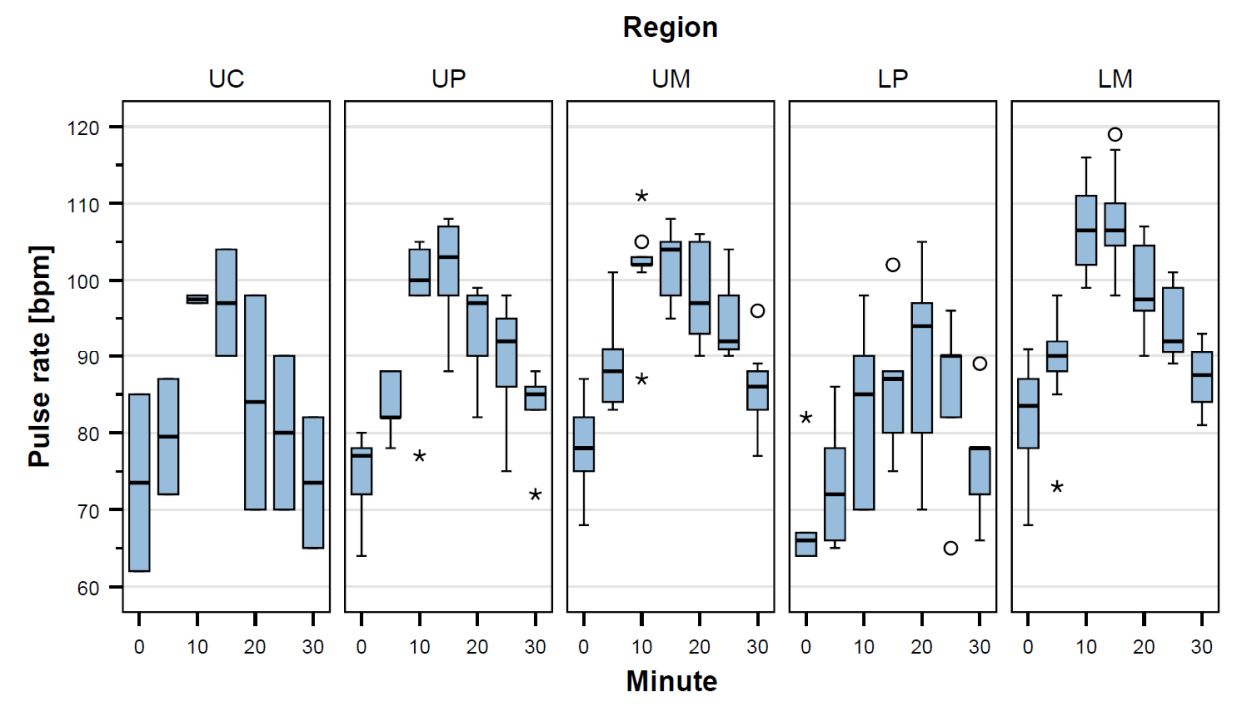

Fig. 3. Relationship between pulse rate and location of 10

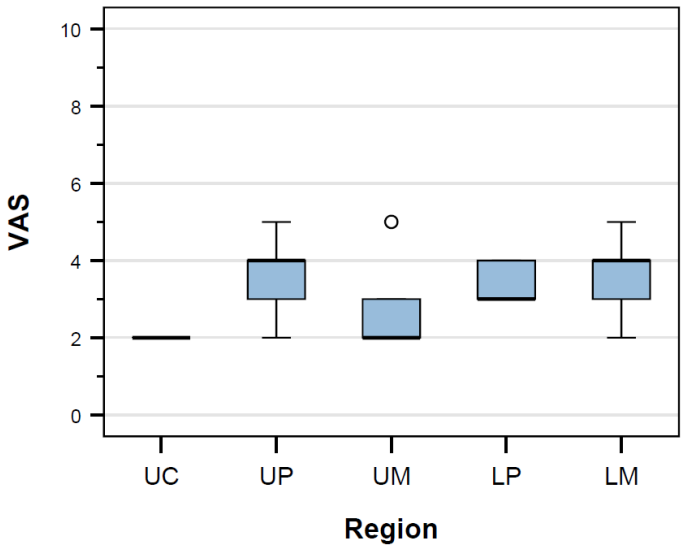

Fig. 4. Relationship between residual pain (VAS) and location of 10 (region)

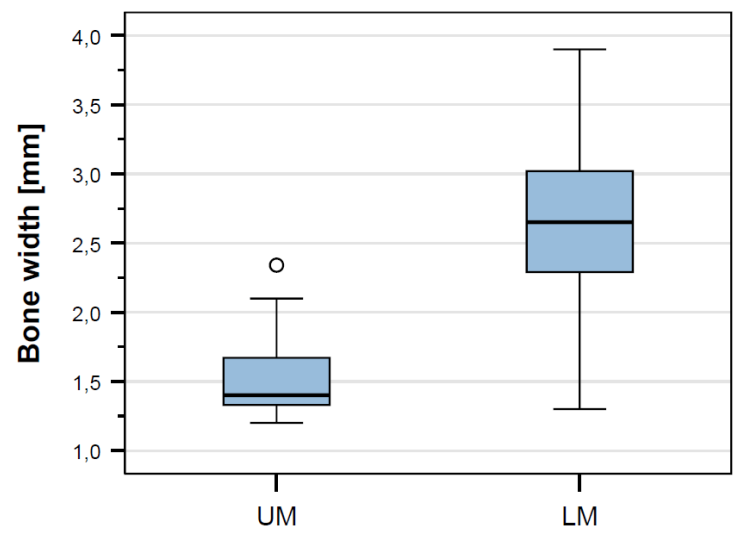

Fig. 5. Relationship between width of the bone $(\mathrm{mm})$ and molar region of 10 (UM / LM)

using the visual analogue scale (VAS) from 0 to 10 , where the 10 represented the worst possible pain. The

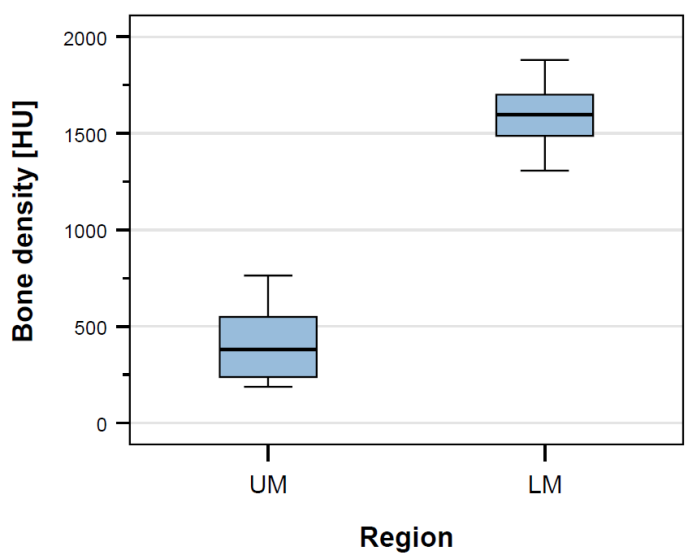

Fig. 6. Relationship between bone density (HU) and molar region of 10 (UM / LM)

participants specified an average VAS score of 3.21 points, with the reported minimum being 2 points and the maximum, 5 points after the treatment.

The average bone width was measured at $2.19 \mathrm{~mm}(1.20$ $\mathrm{mm}-3.9 \mathrm{~mm})$. The average gray scale value was documented as $1092.57 \mathrm{HU}$. The patient heart rates varied between $77.33 \mathrm{bpm}$ at $\mathrm{T} 0$ to $101.18 \mathrm{bpm}$ after $15 \mathrm{~min}$. There were no significant differences in the bone width, density, or heart rate between the sexes.

Correlations between the parameters mentioned above and the IO treated regions were assessed.. The boxplots $3,4,5$, and 6 illustrate the relation of residual pain, pulse rate, bone width, and bone thickness, of the teeth with pulpitis (Fig. 3-6) 
Table 1. Correlation between Pain, bone width, bone density, and pulse rate

\begin{tabular}{|c|c|c|c|c|c|c|c|c|c|c|}
\hline \multicolumn{11}{|c|}{ Statistics for test ${ }^{a, b}$} \\
\hline & VAS & $\begin{array}{c}\text { Bone width } \\
\text { mean } \pm \text { SD } \\
{[\mathrm{mm}]}\end{array}$ & $\begin{array}{c}\text { Bone density } \\
\text { mean } \pm \text { SD } \\
{[\mathrm{HU}]}\end{array}$ & $\begin{array}{c}\text { Pulse rate } \\
0 \text { [min] }\end{array}$ & $\begin{array}{l}\text { Pulse rate } \\
5 \text { [min] }\end{array}$ & $\begin{array}{l}\text { Pulse rate } \\
10 \text { [min] }\end{array}$ & $\begin{array}{c}\text { Pulse rate } \\
15 \text { [min] }\end{array}$ & $\begin{array}{c}\text { Pulse rate } \\
20 \text { [min] }\end{array}$ & $\begin{array}{c}\text { Pulse rate } \\
25 \text { [min] }\end{array}$ & $\begin{array}{c}\text { Pulse rate } \\
30 \text { [min] }\end{array}$ \\
\hline Kruskal-Wallis $\mathrm{H}$ & 9.846 & 9.784 & 14.737 & 10.131 & 14.851 & 17.046 & 13.935 & 3.537 & 8.802 & 9.459 \\
\hline df & 4 & 1 & 1 & 4 & 4 & 4 & 4 & 4 & 4 & 4 \\
\hline $\begin{array}{l}\text { asymptotic } \\
\text { significance }\end{array}$ & 0.043 & 0.002 & 0.000 & 0.038 & 0.005 & 0.002 & 0.008 & 0.472 & 0.066 & 0.051 \\
\hline
\end{tabular}

${ }^{a}$ Kruskal-Wallis-Test, ${ }^{b}$ Group variable: region

Kruskal-Wallis-test and group variable: "region"

Table 2. Correlation between VAS, bone width and bone density

\begin{tabular}{llccc}
\hline \multicolumn{5}{c}{ Correlations } \\
\hline \multirow{3}{*}{ Spearman-Rho } & & Bone width mean \pm SD [mm] & Bone density mean \pm SD [HU] \\
\hline & VAS & Correlation coefficient & $0.612^{* *}$ & 0.280 \\
& Sig. (2-side) & 0.003 & 0.219 \\
\hline & $N$ & 21 & 21 \\
\hline
\end{tabular}

${ }^{* *}$ Correlation is significant: $P \leq 0.01$

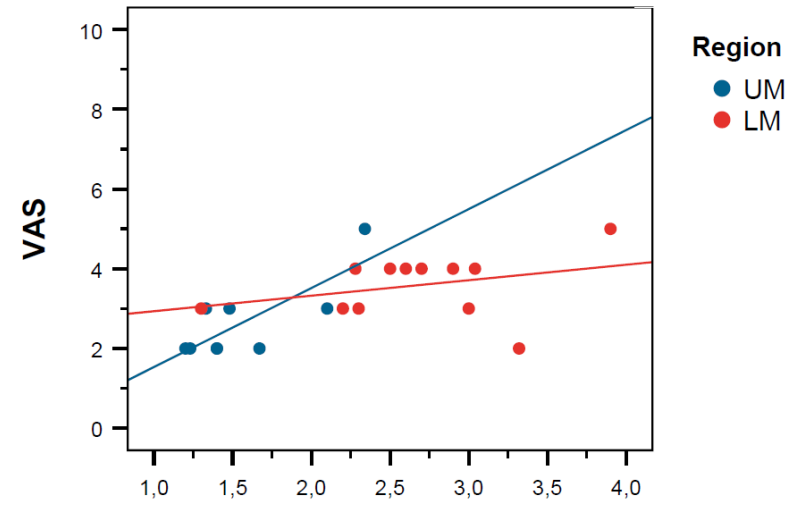

Bone width [mm]

Fig. 7. Relationship between VAS, bone width molar region of IO (UM / LM)

The Kruskal-Wallis test was performed to examine the dependence of the named parameters at the different regions, where the IO was performed (Table 1).

Significant differences were seen in the parameters: VAS, bone width, bone density, and heart rate, between $\mathrm{T} 0$ and $\mathrm{T} 15$ at different regions (Kruskal-Wallis test, $\mathrm{P}$ $<0.05$ / red marking). Thus, selected post-hoc pair-wise comparisons were performed for these coherences.

The upper molar region was compared to that of the lower molar region. Significant differences were observed in heart rate at $\mathrm{T} 15(\mathrm{P}=0.036)$, in VAS $(\mathrm{P}=0.021)$, in bone width $(\mathrm{P}=0.002)$, and bone density $(\mathrm{P}=0.000)$.

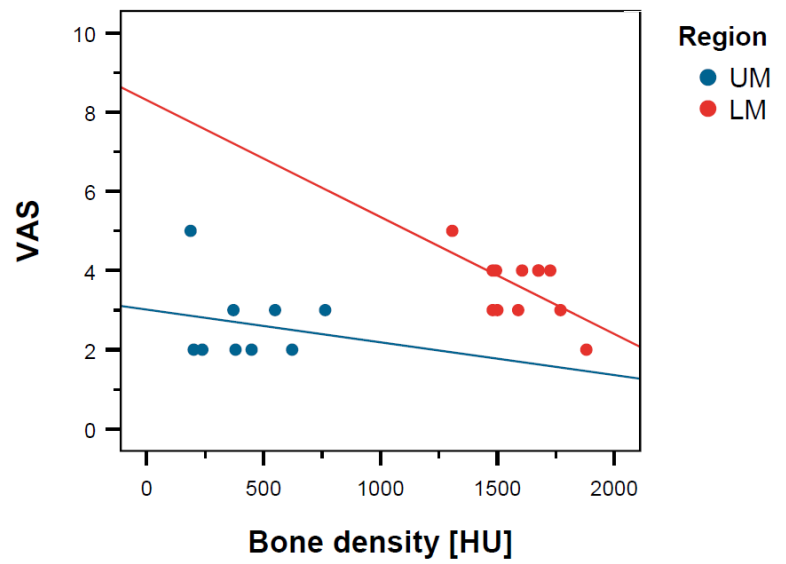

Fig. 8. Relationship between VAS, bone density $(\mathrm{HU})$, and molar region of 10 (UM / LM)

No significant differences were detected for heart rates at $\mathrm{T} 20$ to $\mathrm{T} 30$ ( $\mathrm{P} \geq 0.05 /$ gray markings). Moreover, further examinations were not performed.

A moderate correlation was demonstrated between the VAS score and bone density (Spearman-Rho $[$ IRI $]=0.280$ ). A significant correlation (IRI $=0.612$ ) was found between the VAS score and bone width $(\mathrm{P}<0.01)$ (Table 2).

Fig. 7 illustrates the coherence between pain perception and bone width at the posterior maxilla (UM; blue straight) and at the posterior mandible (LM; red straight) (Fig. 7). By analogy, Fig. 8 shows the link between pain perception and bone density at the posterior maxilla (UM; 
blue straight) and at the posterior mandible (LM; red straight).

\section{DISCUSSION}

Pain control of the mandibular molars with irreversible pulpal pain is one of the greatest challenges during pulp extirpation for root canal preparation. Jung et al. [2] reported a success rate of 70\% using IANB in non-inflamed pulps. However, this decreased quickly to $30 \%$ when irreversible pulpitis was present. The failure rate was reported as approximately eight times higher. Therefore, alternatives to conventional nerve blocks need to be considered for in-depth anesthesia of the lower molars.

The first working assumption, namely that the IO improves analgesia in teeth with irreversible pulpitis was confirmed by the results of this study. The electrical pulp test showed a $95.76 \%$ positive reaction when anesthesia with IANB/IA and IO was administered. In females, the additive IO had a positive effect of $97.22 \%$ and in males, $94.00 \%$.

The participants included in this study assessed their residual pain during treatment and reported an average VAS score of 3.21 points. However, none of the patients were completely pain free. The maximum pain experienced subjectively was plotted at five points.

The efficiency of the IO alone was assessed to be limited but combined with an IA or IANB, the efficacy was enhanced, as demonstrated in the current study. One study, in which IO was used as the main anesthesia compared to a single IANB, concluded that the IO showed a better success rate than the IANB for anesthesia of lower molars with irreversible pulpitis [3]. Farhad et al. [3] included 60 patients and investigated the success rate, effect on blood pressure, and pain relief. After injecting 3\% mepivacain, the success rate of pulpal anesthesia was compared using pulp tests in both groups. The systolic and diastolic blood pressures of the patients were documented before and after injection. The severity of pain during injection was rated using the VAS. The success rate of pain relief of IO during treatment (56.7\%) was significantly higher than that of IANB (23.3\%) (P $=0.008)$. Both techniques showed no significant difference in pain during injection $(\mathrm{P}=0.304)$, and systolic $(\mathrm{P}=0.080)$ or diastolic $(\mathrm{P}=0.28)$ blood pressure after injection [3]. In a commentary of the study by Collier (2018), he highlighted that the success rate of IANB as the primary technique for lower molars with irreversible pulpitis was assumed to be $18.9 \%$ only [4] and that this may be caused by methodological flaws. This further emphasizes the suitability of the IO as the primary technique for anesthesia for these teeth. Martinez et al. [5] tested IO in comparison with IANB for hot teeth in the posterior mandibular region. In the IO group (n $=22$ ), there was no need for additional anesthesia in $62.85 \%$ of patients. The IANB group $(n=23)$ was comparable, with $65.71 \%$ of patients. However, the IO was graded as more comfortable by the participants [5].

Both techniques failed to provide total pulpal anesthesia [3]. Since pain relief using the IANB in hot teeth of the posterior mandible is generally reported as problematic ( $25 \%$ by Shapiro et al. [6]; $28.1 \%$ by Shahi et al. [7]; 30\% by Jung et al. [2]), the combination of IO and IANB, as in the current study, seems to be a reasonable alternative $[2,6,7]$.

Our results showed a success rate of $95.76 \%$ when IO was combined with IA/IANB. This is a better outcome than combined intraligamentous injection (ILA) or a buccal infiltration with IANB. Shahi et al. [7] reported a success rate of $75 \%$ for IANB combined with ILA and $65.6 \%$ for IANB combined with buccal infiltration [7].

Pereira et al. [8] reported a similar success rate of IO as the sole anesthesia. They did not inject with $1.7 \mathrm{ml}$ ultracain forte 1:100000 epinephrine hydrochloride as in the current study, but with $9 \mathrm{~mL}$ of $4 \%$ articaine with 1:100000 or 1:200000 adrenalin. This allowed them to reach an anesthetic efficiency of $96.8 \%$, rather than $93.1 \%$. Only minimum cardiovascular side effects were reported [8]. Demir et al. [9] in their study published in 2020 , used $1.8 \mathrm{ml}$ of $2 \%$ articaine for sole IO during osteotomy of impacted third molars and described less 
pain during the extraction procedure compared to IANB [9].

An investigation of 40 emergency patients from 2013 by Razavian et al. [10], did not find any significant differences regarding the success rates of IO and IANB as the primary anesthetic technique for mandibular molars with irreversible pulpitis. The success rates were also documented as high (85\% using IO versus $70 \%$ using IANB). The authors asked the readers to bear in mind that the necessary technical equipment for IO is expensive and that there is a risk of injuring the dental root and causing temporary tachycardia. They advised against using $\mathrm{IO}$ as the primary technique [10].

The second working assumption was about the rapid onset and the short effect of duration, as confirmed by the present results. The duration of IO was on average less than a quarter of an hour (13.03 min). It lasted longer in females than in males (13.61 min versus $12.33 \mathrm{~min}$ ). The shortest duration was 5 min. The longest duration of anesthesia was reported as an average of $18.75 \mathrm{~min}$ for the lower molars of female participants.

Vongsavan et al. [11] administered IO to the lower molars of 10 voluntary healthy participants who did not suffer from pulpitis. The onset of the effect took an average of $2.40 \pm 0.84$ mins and lasted on average 38 \pm 16.19 mins [11]. These results probably reflect the psychological impact of anticipatory pain, which was not present in the healthy patients.

The third working assumption was also confirmed by the findings of this study. In the female group, $44.4 \%$ of inflamed teeth were found in the lower molar region, and $26.7 \%$ in the male group. Every third tooth requiring endodontic treatment was located in the posterior area of the mandible (36.4\%). This makes the region the most affected. An investigation by Hertel et al. [12] found that $56.6 \%$ of inflamed teeth were in the lower jaw and most of them $(44.3 \%)$ were molars. In the current study, the lower molar region had the highest bone width and density. Treatment of hot teeth in this area was related to a higher pulse rate and higher residual pain sensation. A moderate correlation (Spearman-Rho $[\mathrm{IRI}]=0.280$ ) was found between the VAS score and bone width, and a clearly visible correlation (IRI $=0,612)$ was also noted between subjective residual pain sensation and bone width. There was no gender specificity. The authors have been working with various devices for intraosseous anesthesia for 15 years. In non-inflammatory cases, such as for small oral surgical operations for tooth extractions or osteotomies, exclusive anesthesia with IO is possible without complications.

Based on the fourth working assumption, a change in heart rate with supplementary IO should be reviewed. The IO has a reputation to increase the heart rate. Replogle et al. [13] showed that heart rates returned to the starting point within $4 \mathrm{~min}$. The temporary increase was classified as clinically irrelevant for non-burdened patients. For patients with cardiovascular diseases, an injection with $3 \%$ mepivacain solution was recommended, instead of 2\% Lidocaine-adrenaline solution [13]. Guglielmo et al. [14] reported an average increase in heart frequency of 23-24 beats per minute after IO in $80 \%$ of their participants [14]. The heart rate of the 33 patients in this study varied between 77.3 heartbeats/min at $\mathrm{T} 0$ and a pulse of 101.18 after 15 minutes. Thus, the results concurred with the results of previous studies. Comparative studies that determined the pulse rate in conventional anesthetic techniques (IA and IANB), showed that there is a temporary increase in heart rate when using IA or IANB. The heart rate was normalized for IANB after 2 min [15]. In comparison, IA triggered a significantly higher increase in the heart rate than IANB [9].

\section{CONCLUSION}

These results suggest that a painful treatment, subjectively feared by most of the participants, can be reduced significantly by using an additional IO. IO for prolongation and deepening of local analgesia is advantageous for the treatment of teeth with irreversible pulpitis. Emphasis should be placed on the very precise 
anesthetic effect into the jaw, and therefore, a small amount of anesthetic solution is needed. This is a benefit, especially for treating patients with risks. Nevertheless, the application of IO in comparison to the use of other local anesthesia requires precise knowledge of the individual anatomy of the patient. The decision to use IO for an individual patient, and considerations regarding the suitability of IO for a particular procedure rest upon the clinician, who must use their expert knowledge and skills to optimize the treatment and minimize all associated risks.

\section{Abbreviations:}

BPM: Beats per minute

CBCT: Cone-beam-computer-tomography

IA: Infiltration anesthesia

IAL: Intraligamentary anesthesia

IANB: Inferior alveolar nerve block

IO: Intraosseous anesthesia

IP: Irreversible pulpitis

HR/PR: Heart rate / Pulse rate

HU: Hounsfield units

VAS: Visual analog-scale

\section{Different regions of the mouth:}

UM: Upper molar region

UP: Upper premolar region

UC: Upper canine region

UI: Upper incisivus region

LI: Lower incisivus region

LC: Lower canine region

LP: Lower premolar region

LM: Lower molar region

\section{AUHOR ORGIIS}

Manfred Nilius: https://orcid.org/0000-0003-0297-4012

Charlotte Mueller: https://orcid.org/0000-0001-7581-2896

Minou Helene Nilius: https://orcid.org/0000-0003-4789-7882

Dominik Haim: https://orcid.org/0000-0002-5299-3468

Henry Leonhardt: https://orcid.org/0000-0003-1412-0276

Guenter Lauer: https://orcid.org/0000-0001-7536-0885
AUHOR GONHRBUIONS

Manfred Nilius: Conceptualization, Data curation, Formal analysis, Investigation, Methodology, Supervision, Writing - original draft

Charlotte Mueller: Methodology, Project administration, Writing review \& editing

Minou Helene Nilius: Conceptualization, Writing - review \& editing

Dominik Haim: Writing - review \& editing

Henry Leonhardt: Conceptualization

Guenter Lauer: Supervision

NOTE: There are no conflicts of interest to declare.

\section{REFERENCES}

1. Pröbster L. Intraossäre Anästhesie als Alternative zur herkömmlichen Infiltrations- und Leitungsanästhesie. Quintessenz, 2012; 63: 71-6.

2. Jung IY, Kim JH, Kim ES, Lee CY, Lee SJ. An evaluation of buccal infiltrations and inferior alveolar nerve blocks in pulpal anesthesia for mandibular first molars. J Endod 2008; 34: 11-3.

3. Farhad A, Razavian H, Shafiee M. Effect of intraosseous injection versus inferior alveolar nerve block as primary pulpal anaesthesia of mandibular posterior teeth with symptomatic irreversible pulpitis: a prospective randomized clinical trial. Acta Odontol Scand 2018; 76: 442-7.

4. Collier T. Intraosseous anaesthesia as a primary technique for mandibular posterior teeth with symptomatic irreversible pulpitis. Acta Odontol Scand 2018; 76: 535-7.

5. Martínez Martínez A, Lujan Pardo MD, Harris Ricardo J. Perception of discomfort during injection and the need for supplemental anesthesia in the intraosseous technique using 4\% articaine. Acta Odontol Latinoam 2016; 29: 214-8.

6. Shapiro MR, McDonald NJ, Gardner RJ, Peters MC, Botero TM. Efficacy of articaine versus lidocaine in supplemental Infiltration for mandibular first versus second molars with irreversible pulpitis: a prospective, tandomized, double-blind Clinical Trial. J Endod 2018; 44: 523-8. 
7. Shahi S, Rahimi S, Yavari HR, Ghasemi N, Ahmadi F. Success rate of 3 injection methods with articaine for mandibular first molars with symptomatic irreversible pulpitis: a CONSORT randomized double-blind clinical trial. J Endod 2018; 44: 1462-6.

8. Pereira LA, Groppo FC, Bergamaschi Cde C, Meechan JG, Ramacciato JC, Motta RH, et al. Articaine (4\%) with epinephrine $(1: 100,000$ or 1:200,000) in intraosseous injections in symptomatic irreversible pulpitis of mandibular molars: anesthetic efficacy and cardiovascular effects. Oral Surg Oral Med Oral Pathol Oral Radiol 2013; 116: e85-91.

9. Demi E, Ataoglu H. Clinical evaluatin of efficacy of transcortical anesthesia for the extraction of impacted mandibular third molars: a randomized controlled trial. J Dent Anesth Pain Med 2020; 20: 9-17.

10. Razavian H, Kazemi S, Khazaei S, Jahromi MZ. X-tip intraosseous injection system as a primary anesthesia for irreversible pulpitis of posterior mandibular teeth: a randomized clinical trail. Dent Res J (Isfahan) 2013; 10: 210-3.

11. Vongsavan K, Samdrup T, Kijsamanmith K, Rirattanapong $\mathrm{P}$, Vongasavan $\mathrm{N}$. The effect of intraosseous local anesthesia of 4\% articaine with 1:100,000 epinephrine on pulpal blood flow and pulpal anesthesia of mandibular molars and canines. Clin Oral Investig 2019; 23: 673-80.

12. Hertel M, Sommer K, Kostka E, Imiolczyk S, Ballout H, Preissner S. Outcomes of endodontic therapy comparing conventional sodium hypochlorite irrigation with passive ultrasonic irrigation using sodium hypochlorite and ethylenediaminetetraacetate. a retrospective analysis. Open Dent J 2016; 12: 375-81.

13. Replogle K, Reader A, Nist R, Beck M, Weaver J, Meyers WJ. Cardiovascular effects of intraosseous injections of 2 percent lidocaine with 1:100,000 epinephrine and 3 percent mepivacaine. J Am Dent Assoc 1999; 130: 649-57.

14. Guglielmo A, Reader A, Nist R, Beck M, Weaver J. Anesthetic efficacy and heart rate effects of the supplemental intraosseous injection of $2 \%$ mepivacaine with 1:20,000 levonordefrin. Oral Surg Oral Med Oral Pathol Oral Radiol Endod 1999; 87: 284-93.

15. Ghoddusi J, Zarrabi MH, Daneshvar F, Naghavi N. Efficacy of IANB and Gow-Gates techniques in mandibular molars with symptomatic Irreversible pulpitis: a prospective randomized double blind clinical study. Iran Endod J 2018; 13: 143-8. 